\title{
Thyroid Hormone Induces Cerebellar Purkinje Cell Dendritic Development via the Thyroid Hormone Receptor $\alpha 1$
}

\author{
Heike Heuer and Carol Ann Mason \\ Department of Pathology, Center for Neurobiology and Behavior, Columbia University, College of Physicians and Surgeons, New York, New York 10032
}

The thyroid hormone L-3,3',5-triiodothyronine (T3) plays an important role during cerebellar development. Perinatal T3 deficiency leads to severe cellular perturbations, among them a striking reduction in the growth and branching of Purkinje cell dendritic arborization. The molecular mechanisms underlying these effects are poorly understood. Despite the well documented broad expression of thyroid hormone receptors (TRs), analysis of different TR-deficient mice has failed to provide detailed information about the function of distinct TRs during neuronal development. The cerebellar cell culture systems offer an excellent model by which to study the effects of T3, because differentiation of cerebellar neurons in mixed and purified cultures proceeds in the absence of serum that contains T3. Addition of T3 to cerebellar cultures causes a dramatic increase in Purkinje cell dendrite branching and caliber in a dose- and time-dependent manner. Furthermore, we demonstrate for the first time that T3 acts on Purkinje cells directly through TR $\alpha 1$ expressed on the Purkinje cell and not on the granule cell, the presynaptic partner of Purkinje cells. In contrast, TR $\beta$ isoforms are not involved, because Purkinje cells derived from TR $\beta^{-l-}$ mice show the same T3 responsiveness as wild-type cells. T3-promoted Purkinje cell differentiation was not mediated via neurotrophins, as suggested previously, because dendritogenesis of Purkinje cells from $\mathrm{BDNF}^{-1-}$ mice could be effectively stimulated in vitro by $\mathrm{T} 3$ treatment. Furthermore, the effects of $\mathrm{T} 3$ observed were not abolished by tyrosine kinase receptor B (TrkB)-IgG, TrkC-IgG, or K252a, agents known to block the actions of neurotrophin. These results indicate that T3 directly affects Purkinje cell differentiation through activation of the TR $\alpha 1$.

Key words: thyroid hormone; T3; TR; Purkinje cell; neurotrophins; BDNF; NT3; K252a; dendrite development; cerebellum

\section{Introduction}

The thyroid hormone L-3,3',5-triiodothyronine (T3) is essential for normal CNS development (Oppenheimer and Schwartz, 1997). T3 deficiency during fetal and neonatal periods causes striking abnormalities in neuronal migration and differentiation, outgrowth of neuronal processes, synaptogenesis, myelination, glial cell proliferation, and neuronal cell death (Legrand, 1984; Anderson, 2001). In humans, if thyroid hormone replacement is not instituted within a critical time window after birth, T3 deficiency leads to the syndrome termed cretinism (Porterfield and Hendrich, 1993).

The development of the murine cerebellum in hypothyroid animals has been extensively examined, especially with regard to Purkinje cell differentiation. Previous studies on hypothyroid rats have revealed abnormal organization of the trunk of the Purkinje cell dendritic tree, persistent hypoplasia of the dendritic field, and a reduction in spine number (Vincent et al., 1982; Legrand, 1984). Proliferation, migration, and differentiation of

\footnotetext{
Received April 29, 2003; revised Aug. 25, 2003; accepted Sept. 24, 2003.

This work was supported by National Institutes of Health Grant R01 NS16951 (C.A.M.), by the Max-PlanckSociety, and by Deutsche Forschungsgemeinschaft (H.H.). We thank Karl Bauer, Peter Scheiffele, Sandra Iden, Chiara Manzini, Mary Morrison, Anna Dunaevsky, Phil Buttery, and Lloyd Greene for helpful discussions, Valerie Ashe for reading this manuscript, and Mika Melikyan and Richard Blazeski for excellent technical assistance.

Correspondence should be addressed to Dr. Carol A. Mason, Columbia University, College of Physicians and Surgeons, 630 West 168th Street, New York, NY 10032. E-mail: cam4@columbia.edu.

H. Heuer's present address: Max-Planck-Institute for Experimental Endocrinology, Feodor-Lynen-Strasse 7 , D-30625 Hannover, Germany.

Copyright $\odot 2003$ Society for Neuroscience $\quad$ 0270-6474/03/2310604-09\$15.00/0
}

granule cells, however, appear to be transiently retarded, although parallel fibers of granule cells are shorter and have fewer synaptic contacts with Purkinje cells (Nicholson and Altman, 1972; Lauder, 1977, 1978). Despite the detailed description of cerebellar development under T3 deficiency, the molecular mechanisms underlying T3-induced Purkinje cell morphogenesis are essentially unknown.

The actions of thyroid hormone are primarily mediated by thyroid hormone receptors (TRs), which belong to the family of nuclear hormone receptors containing a DNA-binding and a ligand-binding domain (Mangelsdorf et al., 1995). By interacting with response elements on DNA [thyroid hormone responsive elements (TREs)] and recruiting corepressor or coactivator proteins, TRs can mediate transcriptional control of target genes (Wu and Koenig, 2000; Zhang and Lazar, 2000). Two genes ( $\alpha$ and $\beta$ ) have been identified, and these give rise to different splice variants. Among these are the T3 receptors TR $\alpha 1$ and TR $\beta 1$, both reported to be expressed during rat cerebellar development (Mellström et al., 1991; Bradley et al., 1992). However, the functions of these receptors with regard to Purkinje cell development are not clear, because obvious cerebellar abnormalities have not been noted in thyroid hormone receptor-deficient mice (Forrest and Vennström, 2000; Forrest et al., 2002).

In this study, we used cerebellar cell culture models to analyze the effects of T3 on Purkinje cell dendritic development and to define the receptor involved in this action. Our previous studies indicated that granule cells are potent regulators of Purkinje cell 
development (Baptista et al., 1994; Morrison and Mason, 1998; Shimada et al., 1998). The coculture of purified granule and Purkinje cells allowed us to ask on which cell the key receptors must be expressed: on the Purkinje cell, thus a direct route for T3 stimulation of Purkinje cell dendritic development, or on the granule cell, its presynaptic partner, which would release growthpromoting factors in response to T3 and indirectly mediate the effects of T3 on Purkinje cell differentiation. In addition, we studied the role of BDNF and neurotrophin-3 (NT3) signaling in these cell culture systems, because these neurotrophins have been implicated in collaborations with T3 during cerebellar development (Lindholm et al., 1993; Neveu and Arenas, 1996; Koibuchi et al., 1999).

\section{Materials and Methods}

Animals. Experiments were performed either with C57BL/6J mice or with transgenic mice from a timed pregnancy breeding colony under our direction. Breeding pairs of $\operatorname{TR} \beta^{-1-}$ mice (Forrest et al., 1996), TR $\alpha 1^{-1-}$ mice (Wikström et al., 1998), and $\mathrm{BDNF}^{+/-}$mice (Ernfors et al., 1994) were obtained from The Jackson Laboratory (Bar Harbor, ME). Genotypes of animals were determined using protocols provided by The Jackson Laboratory. For any single Purkinje cell purification experiment, 30 pups at postnatal day 0 (P0)-P1 were used. Granule neurons were purified from 4 -d-old pups. Mixed cerebellar primary cultures were prepared from newborn mice.

Reagents. L-3,3',5-triiodothyronine was purchased from Sigma (St. Louis, MO). Tyrosine kinase receptor B (TrkB)-IgG and TrkG-IgG were kindly provided by Dr. G. Yancopoulos (Regeneron Pharmaceuticals, Tarrytown, NY). K252a and K252b were obtained from Calbiochem (San Diego, CA). BDNF was purchased from Bachem (Weil am Rhein, Germany). Serum-free medium was composed of Eagle's basal medium (BME; Invitrogen, Gaithersburg, MD) supplemented with bovine serum albumin (10 mg/ml; A-8806; Sigma), glutamine (2 mm; Invitrogen), glucose (32 mM), penicillin-streptomycin ( $29 \mathrm{U} / \mathrm{ml}$ each; Invitrogen), and Sigma I-1884 supplement (1:100 dilution, resulting in final concentrations of $5 \mu \mathrm{g} / \mathrm{ml}$ insulin, $5 \mu \mathrm{g} / \mathrm{ml}$ transferrin, and $5 \mathrm{ng} / \mathrm{ml}$ sodium selenite). Serum-containing medium was composed of BME, glutamine, glucose, penicillin-streptomycin, and 10\% horse serum (Invitrogen). Culture surfaces were pretreated overnight at $4^{\circ} \mathrm{C}$ with high-molecularweight poly-D-lysine ( $500 \mu \mathrm{g} / \mathrm{ml}$; Speciality Media, Phillipsburg, NJ) and washed three times with distilled water before use.

Mixed cerebellar cultures. Mixed cerebellar cultures were prepared as published previously (Baptista et al., 1994; Hatten et al., 1998). Briefly, newborn C57BL/6J mice were killed by decapitation. Cerebella were dissected in PBS, and meninges were removed. Tissues were treated with trypsin (1\% in PBS; Worthington, Freehold, NJ) for $3 \mathrm{~min}$ at room temperature (RT). After replacing trypsin with DNase (0.05\% in BME; Worthington), cerebella were triturated successively with three firepolished Pasteur pipettes of decreasing bore sizes. Cells were centrifuged and resuspended in PBS with DNase, and the cell slurry was passed through a $33 \mu \mathrm{M}$ nylon mesh filter. Cells were resuspended in horse serum, diluted 1:8 in serum-free medium, and plated at a density of $11 \times$ $10^{5} \mathrm{cell} / \mathrm{cm}^{2}$ in Lab-Tek (Nunc, Naperville, IL) 7-mm-diameter wells (300,000 cells/well in $0.2 \mathrm{ml})$. Plated cells were allowed to attach overnight, and then the medium was changed to complete serum-free medium that included reagents of interest. Thereafter, medium (including reagents of interest) was replaced every 3-4 d over a $14 \mathrm{~d}$ culture period.

Purkinje cell-granule cell cocultures. Cerebellar Purkinje cells and granule neurons were purified as described previously (Baptista et al., 1994; Hatten et al., 1998; Morrison and Mason, 1998). For granule cell purification, dissociated cells were subjected to a Percoll gradient. The dense cell fraction at the interface between the 35 and $60 \%$ Percoll phases was collected, and non-neuronal cells were removed by two sequential platings on Petri dishes precoated with $100 \mu \mathrm{g} / \mathrm{ml}$ poly-D-lysine. Nonadherent neuronal cells were collected and plated under serum-free conditions at a density of $11 \times 10^{5}$ cells $/ \mathrm{cm}^{2}$ onto poly-D-lysine-coated Lab-Tek wells (Nunc) (300,000 cells per well). These cultures typically consisted of at least $95 \%$ granule cells and $<5 \%$ GFAP-positive cells. Cells with the morphological characteristics of oligodendroglia could not be detected (Hatten, 1985; Baptista et al., 1994).

Purkinje cell-enriched preparations were obtained by passing papaindissociated cerebellar cells over a 35\% Percoll cushion. Non-neuronal cells as well as the majority of contaminating granule cells were removed by negative immunopanning using anti-GD3 supernatant (HB-8448, from the R24 hybridoma; American Type Culture Collection, Manassas, VA). Purkinje cells were selected by positive immunopanning using antiThy1.2 (Leinco Technologies, St. Louis, MO) and released from the surface with trypsin. After sedimentation, Purkinje cells were resuspended in serum-free medium and plated at a density of $\sim 1 \times 10^{5}$ cells $/ \mathrm{cm}^{2}$ (30,000 cells per well in $0.2 \mathrm{ml}$ ) on granule cell monolayers prepared $1 \mathrm{~d}$ before. Cultures prepared this way were composed of at least $90 \%$ calbindin-positive Purkinje cells and $<5 \%$ GFAP-positive glial cells (Baptista et al., 1994; Morrison and Mason, 1998).

Immunocytochemical analysis of Purkinje cell morphology. Purkinje cells were visualized as published previously (Morrison and Mason, 1998). Briefly, cultures were fixed with $4 \%$ paraformaldehyde at room temperature for $60 \mathrm{~min}$ and immunostained with a rabbit polyclonal antibody against calbindin D28k (1:2000; Swant, Bellinzona, Switzerland) followed by incubation with a cyanine 3 (Cy3)-labeled goat antirabbit antibody (1:400; Jackson ImmunoResearch, West Grove, PA). Calbindin-positive Purkinje cells were photographed with an Axiocam digital camera (Zeiss, Oberkochen, Germany) on an Axiophot microscope $(63 \times$ objective). All experiments were performed at least three times. To quantify dendritic outgrowth, the total area covered by the soma and dendritic tree on randomly selected Purkinje cells $(n=20)$ in each experiment was determined by tracing the outline of the cell and dendritic branches and computing the area using NIH Image software. The values are expressed as mean \pm SEM, and results from one experiment are shown graphically. Statistical significance was determined by an unpaired Student's $t$ test and defined as ${ }^{\star} p<0.01$ or as ${ }^{\star \star} p<0.001$.

In situ hybridization combined with immunocytochemistry. Digoxigenin (Dig)-labeled RNA probes for the detection of TR $\alpha 1$ and TR $\beta 1$ transcripts were generated according to standard protocols (Ehrchen et al., 2001). cDNA fragments corresponding to nucleotides 1115-1446 of mouse thyroid hormone receptor $\alpha 1$ (GenBank accession number X51983) and nucleotides 271-495 of mTR $\beta 1$ (NM_009380) subcloned in pGEM-T easy vector (Promega, Mannheim, Germany) were kindly provided by S. Friedrichsen (MPI, Hannover, Germany) and used as templates for in vitro transcription. Probes were diluted to a final concentration of $5 \mu \mathrm{g} / \mathrm{ml}$ in hybridization buffer consisting of $50 \%$ formamide, $10 \%$ dextran sulfate, $0.6 \mathrm{M} \mathrm{NaCl}, 10 \mathrm{~mm}$ Tris-HCl, $\mathrm{pH} 7.4,1 \times$ Denhardt's solution, $0.1 \mathrm{mg} / \mathrm{ml}$ tRNA, $100 \mu \mathrm{g} / \mathrm{ml}$ sonicated salmon sperm DNA, 1 mm EDTA-di-Na, and $10 \mathrm{~mm}$ dithiothreitol. In situ hybridization was performed as described previously (Ehrchen et al., 2001) on mixed cerebellar cultures grown on Lab-Tek slides (Nunc) for $14 \mathrm{~d}$ in the presence or absence of $1 \mathrm{~nm}$ T3. Cultures were fixed in $4 \%$ buffered paraformaldehyde for $1 \mathrm{hr}$, treated with $0.1 \%$ Triton X-100 in PBS for 10 min, and acetylated $(0.25 \%$ acetic anhydride in $0.1 \mathrm{M}$ triethanolamine, $\mathrm{pH}$ 8.0) for $10 \mathrm{~min}$ to reduce nonspecific labeling. After applying hybridization mix, Lab-Tek slides (Nunc) were coverslipped and incubated in a humid chamber at $50^{\circ} \mathrm{C}$ for $16 \mathrm{hr}$. After hybridization, coverslips were removed in $2 \times \mathrm{SSC}(0.3 \mathrm{M} \mathrm{NaCl}$ and $0.03 \mathrm{M}$ sodium citrate, $\mathrm{pH} 7.0)$, and the cells were treated with RNase A $(20 \mu \mathrm{g} / \mathrm{ml})$ and RNase T1 $(1 \mathrm{U} / \mathrm{nl})$ at $37^{\circ} \mathrm{C}$ for $30 \mathrm{~min}$. Successive washes followed at RT in $1 \times, 0.5 \times$, and $0.2 \times$ SSC for $20 \mathrm{~min}$ each and in $0.2 \times$ SSC at $65^{\circ} \mathrm{C}$ for $1 \mathrm{hr}$. For detection of Dig-labeled probes, cells were exposed overnight to alkaline phosphatase-conjugated anti-digoxigenin antibody (final dilution, 1:5000; Roche Diagnostics, Mannheim, Germany) at $4^{\circ} \mathrm{C}$, followed by a $16 \mathrm{hr}$ incubation at RT in chromagen solution containing $0.41 \mathrm{M} \mathrm{ni-}$ troblue tetrazolium and $0.38 \mathrm{~m}$ 5-bromo-4-chloro-3-indolylphosphate. Thereafter, cells were processed for immunocytochemistry as described above using a polyclonal antibody against calbindin and a monoclonal antibody against GFAP (1:500; Sigma) at the same time. As secondary antibodies, Alexa Fluor 555 goat anti-rabbit IgG and Alexa Fluor 488 goat anti-mouse IgG (both from Molecular Probes, Eugene, OR) were used at a final dilution of 1:500. Cell nuclei were visualized after staining with 0.5 
$\mathrm{mg} / \mathrm{ml}$ Hoechst 33258 (Molecular Probes) for $5 \mathrm{~min}$ at room temperature. The cultures were examined by bright-field illumination as well as epifluorescence using an AX70 microscope $(100 \times$ objective; Olympus Optical, Tokyo, Japan) equipped with the appropriate filters and photographed using a DP50 digital camera (Olympus Optical), followed by image manipulation with Adobe Photoshop (Adobe Systems, San Jose, CA).

\section{Results}

T3 induces Purkinje cell dendritic development in a dose- and time-dependent manner

As an initial approach to explore the involvement of T3 in Purkinje cell dendrite development, mixed cerebellar cell cultures were prepared; aside from Purkinje cells and granule cells, these cultures contain other interneurons as well as astroglia. They were kept under serum-free conditions with or without addition of $\mathrm{T} 3$ at different concentrations. After $14 \mathrm{~d}$ in vitro, cultures were fixed and immunostained with an anti-calbindin antibody to visualize Purkinje cells. These neurons respond to rising $\mathrm{T} 3$ concentrations with an increase in dendritic length and caliber as well as an increase in spine numbers. In the absence of T3, dendrites can form, but there is a greater preponderance of cells with multipolar dendritic trees, and the branches, including the dendritic stems, are thinner. With T3 added, numerous sculpted spines covered the dendrites, in contrast to the more elongated and filopodial spines on Purkinje cells without T3 (Fig. 1A). To quantify these effects, Purkinje cells from two different wells were randomly selected, and their shape was determined by measuring the area covered by their soma and dendritic tree using NIH Image software. As shown in Figure $1 B$, dendritic extent increases as T3 concentration rises, reaching an optimal factor of 3 at 3 nм T3.

To determine the temporal response of T3-induced Purkinje cell arborization, cultures were treated with $1 \mathrm{nM}$ T3, a concentration equal to T3 serum levels in adult mice (Friedrichsen et al., 2003), only for a certain period of time. In the first set of experiments, serum-free medium was supplemented with $1 \mathrm{nM} \mathrm{T3}$ at day 10, 7, 5, 3 , or 1 in vitro (Fig. $1 C$, left column). In a complementary set of experiments, cells were plated in the presence of $1 \mathrm{nM} \mathrm{T3}$, but T3 was withdrawn by changing to serumfree medium at day $1,3,5,7$, or 10 in vitro (Fig. $1 C$, right column). All cultures were then analyzed after $14 \mathrm{~d}$ in vitro. Quantification of Purkinje cell morphology revealed that continuous T3 treatment during the entire culture period is required for optimal dendritic growth (Fig. $1 D$ ), in that even if T3 is withheld for a few days, dendrites did not reach the full extent of differentiation. Likebar, $40 \mu \mathrm{m}$.
A

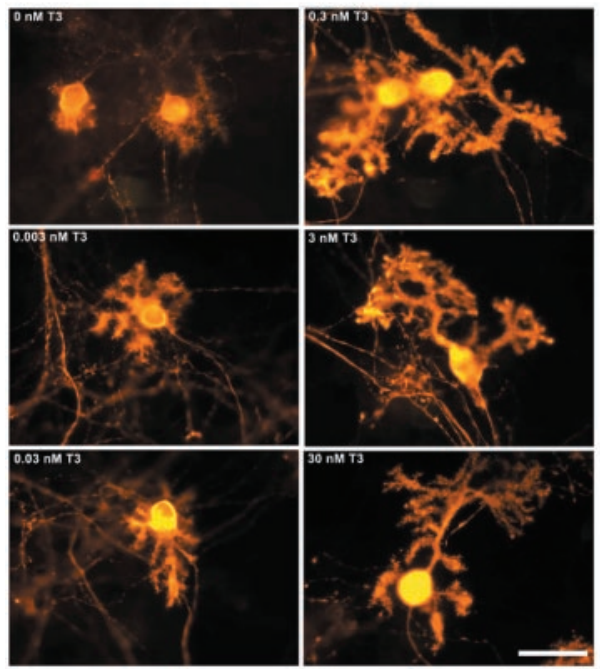

D

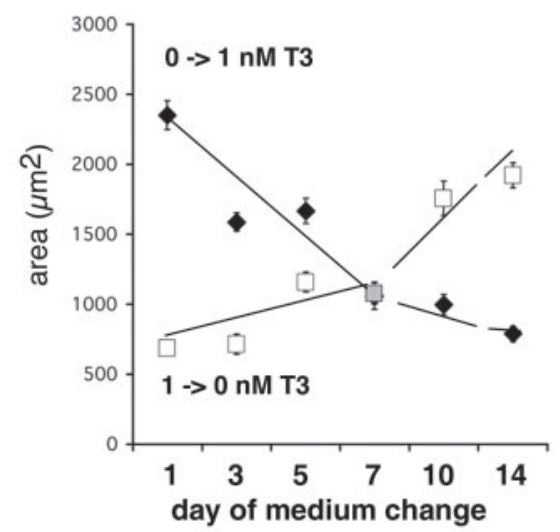

B
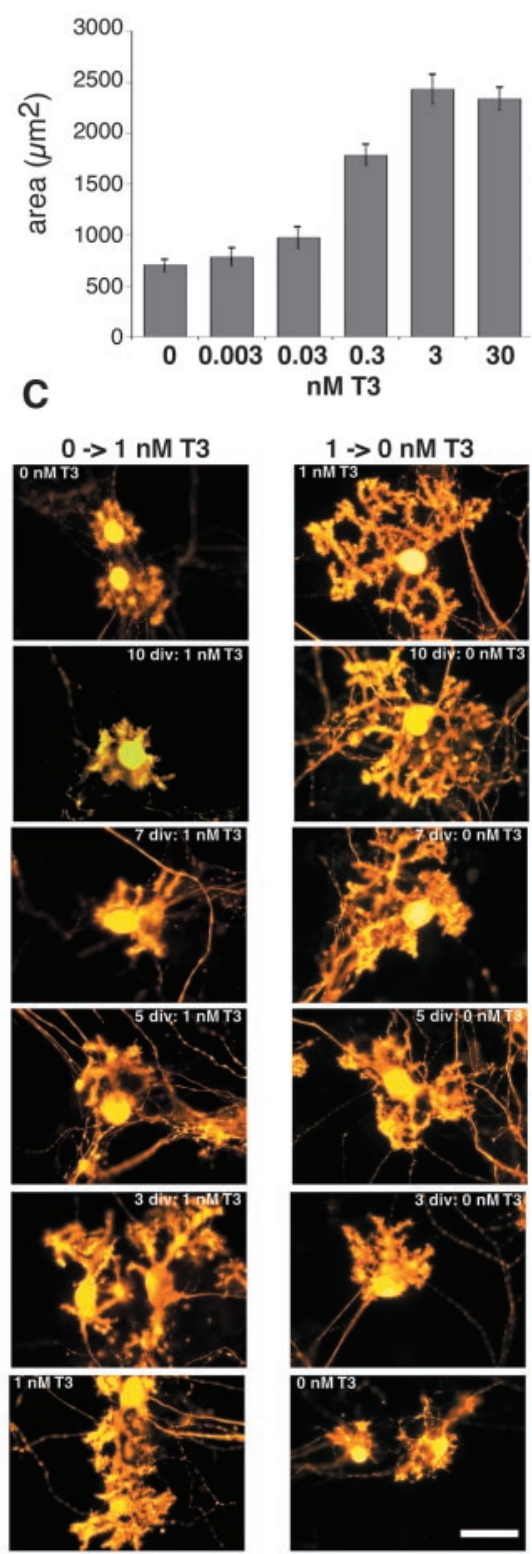

Figure 1. T3 induces Purkinje cell dendritic development in a dose- and time-dependent manner. Mixed cerebellar cultures prepared from neonatal mice were incubated for $14 \mathrm{~d}$ in the presence of varying $\mathrm{T} 3$ concentrations. Purkinje cells were visualized by immunostaining with an antibody against calbindin D28k and a Cy3-coupled secondary antibody. $A$, With rising $T 3$ concentrations, Purkinje cell dendrites become more branched and increase in length and caliber. B, Quantification of the effects of T3: cells were outlined, and the area occupied by the soma and the dendritic tree was measured using NIH Image software. Each column and error bar represents the mean \pm SEM ( $n=20$ Purkinje cells in each group). $C$, To determine the time dependency of the T3 response, mixed cerebellar cultures were cultured for 14 days in vitro (div) and treated with $1 \mathrm{~nm}$ T3 only after 10, 7, 5, or 3 div (left column). Cultures were plated in the presence of $1 \mathrm{~nm}$ T3, but $\mathrm{T} 3$ was subsequently withdrawn by changing to serum-free medium at 10,7,5, or 3 div (right column). As controls, cultures were permanently treated with or without $1 \mathrm{~nm}$ T3. An area of randomly selected Purkinje cells ( $n=20$ for each condition) was measured using NIH Image software. $D$, Area of Purkinje cells after adding T3 (filled diamonds) and area of Purkinje cells after T3 was withdrawn at the time point indicated (open squares). These two sets of experiments revealed that to stimulate optimal Purkinje cell growth, $\mathrm{T} 3$ must be present during the entire culture period. Scale

wise, if T3 was withdrawn, dendrites progressed no further than the stage of development at which T3 was removed.

TR $\alpha 1$ and TR $\beta 1$ are expressed in Purkinje cells in vitro Analysis of TR expression pattern on rat brain sections has revealed that $\operatorname{TR} \alpha 1$ is highly expressed in granule as well as in Purkinje cells (Bradley et al., 1992). In addition, TR $\beta 1$ has been 
reported to be expressed in Purkinje cells exactly during a critical time window of dendritic outgrowth and synaptogenesis in vivo (Strait et al., 1991). To determine whether a similar expression pattern occurs in our in vitro cell culture system, we performed colocalization studies by combining nonradioactive in situ hybridization histochemistry for detecting TR $\alpha 1$ and TR $\beta 1$ isoforms and immunofluorescence labeling for detecting Purkinje cells. In situ hybridization experiments revealed strong labeling for TR $\alpha 1$ and TR $\beta 1$ mRNA in calbindin-positive Purkinje cells (Fig. 2). Therefore, we conclude that Purkinje cells are capable of expressing both TR isoforms in vitro as well as in vivo.

\section{TR $\alpha 1$ but not TR $\beta$ isoforms mediate T3 action on Purkinje cell growth}

To identify the thyroid hormone receptor responsible for the T3-induced dendritic growth, we took advantage of the availability of mice deficient in specific thyroid hormone receptor isoforms. First, we analyzed Purkinje cell differentiation in mixed cerebellar cultures of mice deficient in all known splice variants of the $\operatorname{TR} \beta$ gene. Treatment of the $\operatorname{TR} \beta^{-l-}$ mixed cultures with increasing concentrations of T3 led to the same morphological changes as those observed in wild-type Purkinje cells (Fig. $3 A$ ). Therefore, we conclude that $\mathrm{TR} \beta$ receptor isoforms are not involved in mediating T3-promoted dendritogenesis. Next, we examined transgenic mice deficient in the TR $\alpha 1$ receptor isoform but that still express the non-ligand-binding splice variants TR $\alpha 2$ as well as $\operatorname{TR} \Delta-\alpha-2$ and $\operatorname{TR} \Delta-\alpha-1$. Although the $\operatorname{TR} \alpha 1^{-/-}$derived Purkinje cells show more extensive dendritic outgrowth in T3-free conditions than TR $\beta^{-/-}$-deficient Purkinje cells (Fig. $3 B$ ) or wild-type controls with no T3 present, TR $\alpha 1^{-1-}$-derived Purkinje cells do not respond to T3 treatment by further increasing dendritic area, as shown in Figure 3C. This insensitivity to T3 implies that TR $\alpha 1$ is important for mediating the actions of $\mathrm{T} 3$ on Purkinje cell dendritic differentiation.

\section{T3 acts directly via TR $\alpha 1$ in Purkinje cells}

Because TR $\alpha 1$ has been shown to be widely expressed during cerebellar development, with highest transcript levels in the granule cell layers (Bradley et al., 1989, 1992), it remains to be examined whether T3 influences Purkinje cell dendritic development directly via these receptors on Purkinje cells. Alternatively, granule cells could be the primary target of T3 action, which then in turn would affect Purkinje cell development (e.g., by the synthesis and release of other growth-promoting factors). To address this key question, we took advantage of the cerebellar coculture system developed previously in our laboratory (Baptista et al., 1994). Addition of T3 to cocultures of purified Purkinje cells and purified granule cells led to morphological changes in Purkinje cell dendritic parameters that were the same as those observed in mixed cerebellar cultures (Fig. $4 A$ ), including a robust increase in dendritic caliber and spine density. The same effect was observed if granule cells derived from $\operatorname{TR} \alpha 1^{-/-}$mice were cocultured with wild-type Purkinje cells (Fig. 4B). However, if Purkinje cells were purified from TR $\alpha 1^{-/-}$mice and cocultured with either wild-type or TR $\alpha 1^{-1-}$-derived granule cells, T3 stimulation of Purkinje cell dendritic outgrowth did not occur (Fig. 4C,D). Nonetheless, as already observed in mixed cerebellar cultures, TR $\alpha 1^{-/-}$-derived Purkinje cells cultured under T3-free conditions showed a greater degree of dendritic differentiation than wild-type Purkinje cells (Fig. $4 E$ ). These experiments strongly suggest that T3 acts directly on TR $\alpha 1$ expressed in Purkinje cells to promote dendritic outgrowth.
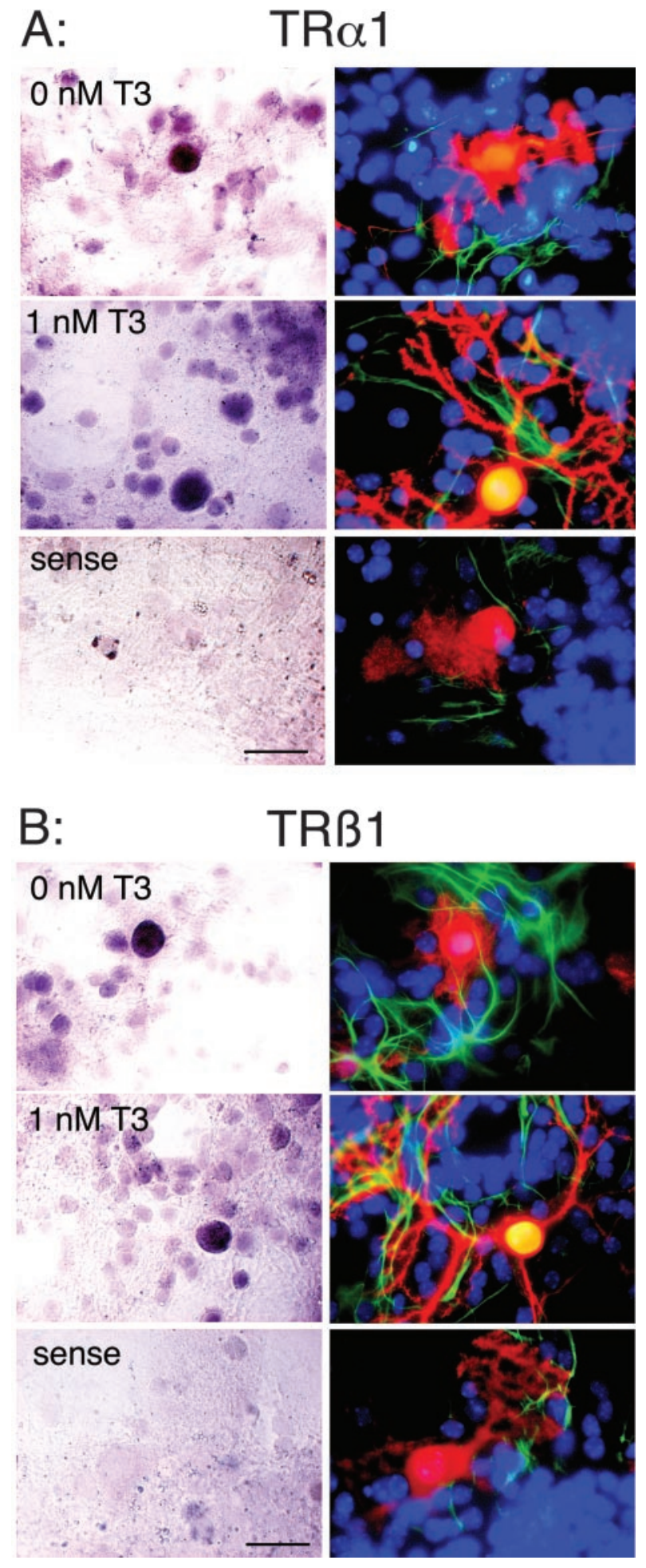

Figure 2. Both TR $\alpha 1$ and TR $\beta 1$ transcripts are present in Purkinje cells in culture. Mixed cerebellar cultures were treated with or without $1 \mathrm{~nm}$ T3 for $14 \mathrm{~d}$. In situ hybridization was performed to detect TR $\alpha 1$ ( $A$, left) and TR $\beta 1$ ( $B$, left) mRNA. Subsequently, the cultures were immunostained against calbindin (red) and GFAP (green) (right). Hoechst staining revealed localization of cell nuclei (blue). For both receptor isoforms, strong hybridization signals were found in cells with large cell bodies that are calbindin-positive and GFAP-negative, indicating that Purkinje cells (but not astrocytes) clearly express both receptor isoforms. Hybridization experiments with the respective sense probe revealed no specific labeling above background. Scale bars, $25 \mu \mathrm{m}$. 


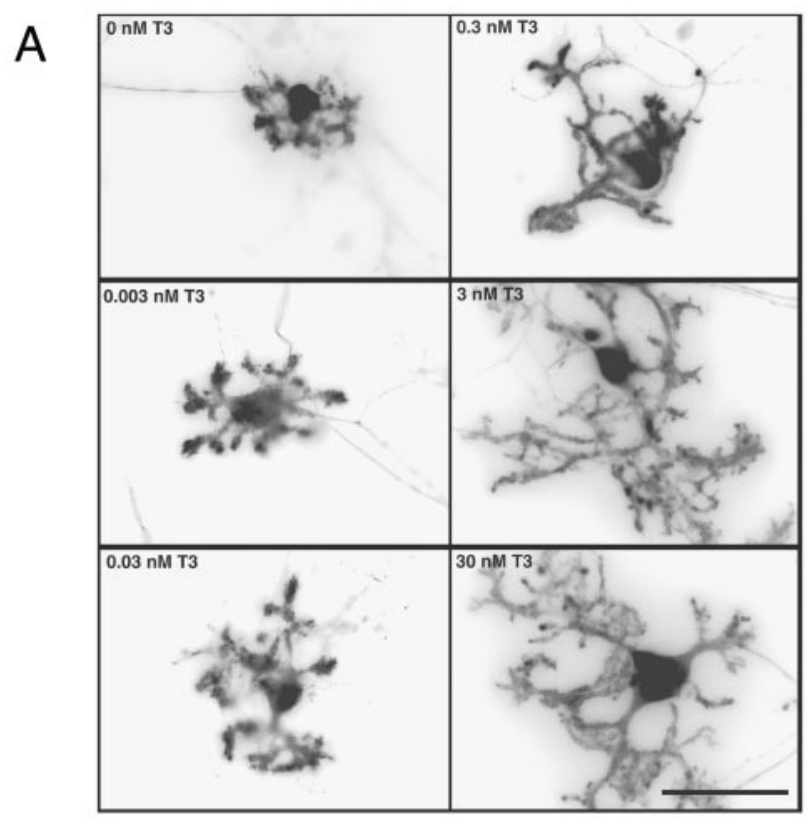

B
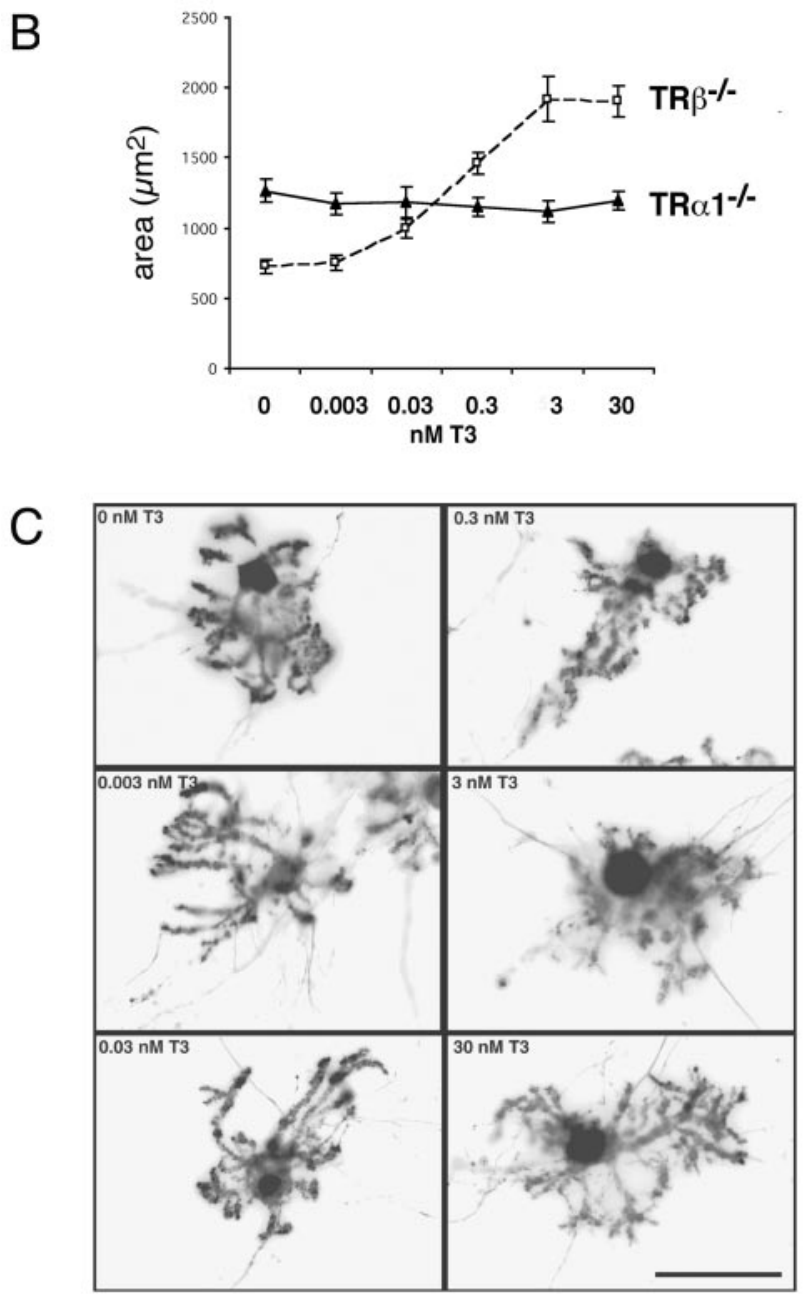

Figure 3. TR $\alpha 1$ but not TR $\beta$ isoform mediates the effects of $T 3$ on Purkinje cell growth. $A$, Purkinje cells in mixed cerebellar cultures derived from TR $\beta^{-\prime-}$ mice show a dose response to T3 treatment that is similar to that seen for wild-type Purkinje cells. $B$, With increasing T3 concentrations, Purkinje cell area increases up to threefold. $B, C$, Purkinje cells in mixed cultures prepared from $T R \alpha 1^{-/-}$mice do not respond to $\mathrm{T} 3$ treatment by increasing dendritic dimensions. Under T3-free conditions, however, they exhibit a higher degree of arborization compared with those from $\operatorname{TR} \beta^{-/-}$mice. Scale bars, $50 \mu \mathrm{m}$.
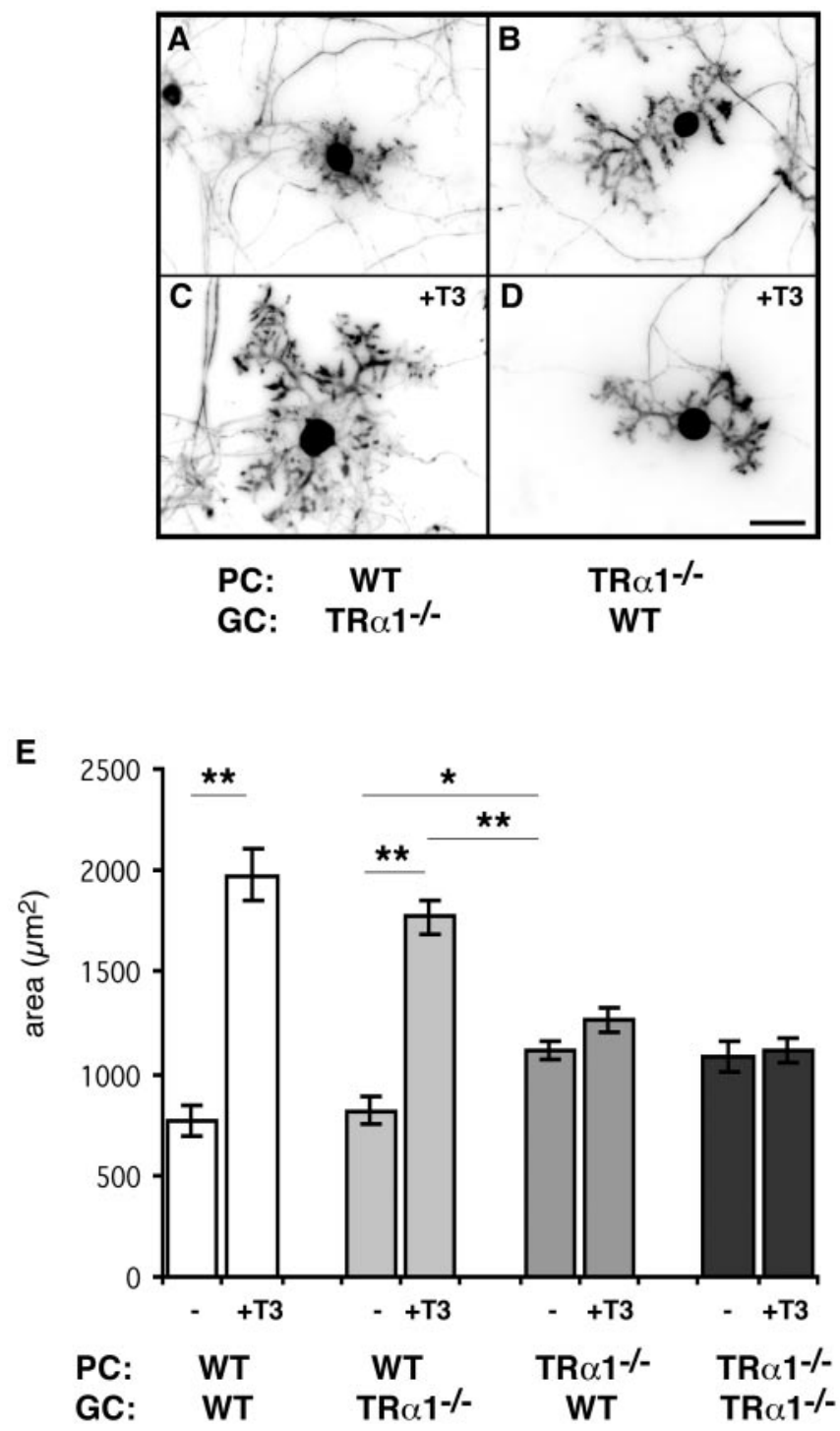

Figure 4. T3 acts directly via TR $\alpha 1$ expressed in Purkinje cells. To distinguish which thyroid hormone receptor mediates the effects of $\mathrm{T} 3$ on Purkinje cells and whether the required receptors must be on Purkinje cells (direct effect) or on granule cells (indirect effect), coculture of purified cells was performed. Purkinje cells purified from wild-type (WT) or TR $\alpha 1^{-/-}$mice were cultured with granule cells purified from TR $\alpha 1^{-1-}$ or wild-type mice and treated with or without $1 \mathrm{~nm}$ T3 for 14 d. A, C, Wild-type Purkinje cells showed T3-promoted dendrite growth even when cultured with TR $\alpha 1^{-1-}$-derived granule cells. B, D, However, Purkinje cells derived from $T R \alpha 1^{-l-}$ mice did not respond to T3 treatment at all, even in the presence of wild-type granule cells. These observations imply that T3 acts directly via TR $\alpha 1$ in Purkinje cells. E, Morphological analysis clearly indicates that TR $\alpha 1^{-1-}$-derived Purkinje cells cultured under T3free conditions showed a higher degree of dendritic differentiation than wild-type Purkinje cells. Data were derived from 20 randomly selected Purkinje cells in each group. Each column and error bar represents the mean \pm SEM. ${ }^{*} p<0.01 ;{ }^{* *} p<0.001$ (by Student's $t$ test). PC, Purkinje cells; GC, granule cells. Scale bar, $40 \mu \mathrm{m}$.

\section{Neurotrophin signaling cascades do not interfere with} T3-induced dendrite growth

Despite the well acknowledged importance of thyroid hormone for proper brain development, little is known about the genes that are regulated by thyroid hormone receptor interactions. Only a few genes containing a TRE have been identified so far, among them members of the neurotrophin family (Koibuchi and Chin, 2000). In the hypothyroid rat model, although transcript levels of BDNF and NT3 are suppressed during cerebellar development, grafting of cell lines expressing NT3 or BDNF into the rat brain 
A
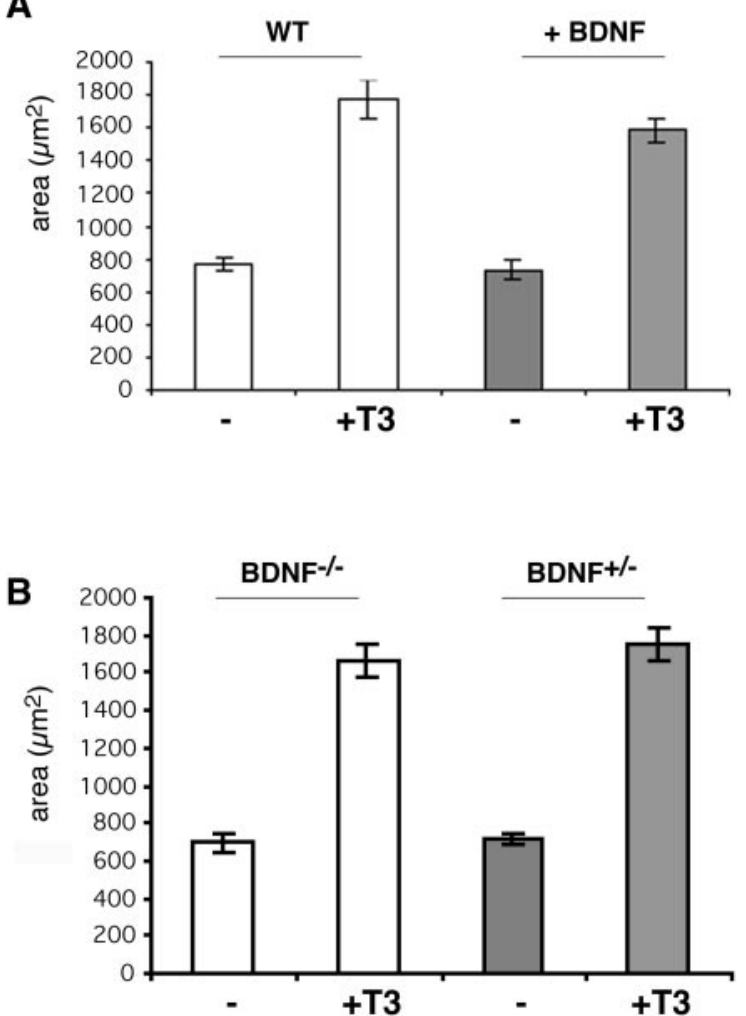

C

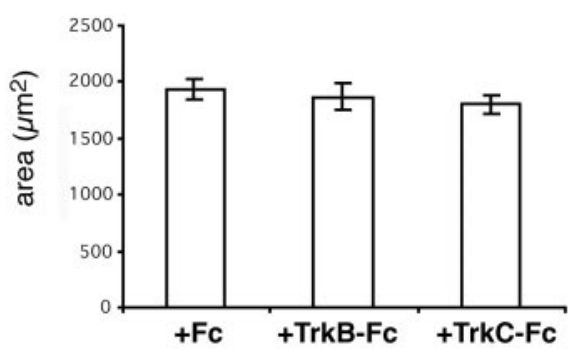

Figure 5. Blocking the actions of neurotrophin does not abolish T3-induced dendrite growth. $A, B D N F(10 \mathrm{ng} / \mathrm{ml})$ was added to mixed cerebellar cultures derived from wild-type (WT) mice every $4 \mathrm{~d}$ in the presence or absence of $1 \mathrm{~nm}$ T3. After incubation for $14 \mathrm{~d}$, Purkinje cell dendritogenesis was analyzed after immunostaining with anti-calbindin. Addition of exogenous BDNF did not further enhance T3-dependent dendritic arborization. B, Mixed cerebellar cultures were prepared from BDNF ${ }^{-1-}$ newborns and their heterozygous littermates. Purkinje cells derived from $\mathrm{BDNF}^{-1-}$ mice showed the same $\mathrm{T3}$-induced increase in dendritic parameters as Purkinje cells prepared from BDNF ${ }^{+/-}$pups. C, To block the actions of neurotrophin, mixed cerebellar cultures were incubated with $1 \mathrm{~nm}$ T3 in the presence of $25 \mu \mathrm{g} / \mathrm{ml} \mathrm{TrkB-Fc} \mathrm{or}$ TrkC-Fc or with $\mathrm{Fc}$ alone (control). None of these agents perturbed T3-promoted dendritogenesis in Purkinje cells. Data were derived from 20 randomly selected Purkinje cells in each group. Each column and error bar represents the mean \pm SEM.

ameliorates cerebellar defects caused by hypothyroidism (Neveu and Arenas, 1996). Because these findings implicate neurotrophins as a direct target of thyroid hormone action, we studied the putative role of neurotrophins with regard to T3-induced Purkinje cell growth. In the first set of experiments, mixed cerebellar cultures were treated with BDNF $(10 \mathrm{ng} / \mathrm{ml})$ for $14 \mathrm{~d}$ in the presence or absence of T3. As illustrated in Figure 5A, adding BDNF had no additional growth-promoting effects on Purkinje cell arborization even in the presence of T3. We then analyzed whether disruption of neurotrophin signaling would affect T3-induced Purkinje cell growth. For this purpose, we prepared mixed cerebellar cultures from newborn $\mathrm{BDNF}^{-1-}$ as well as from heterozy-

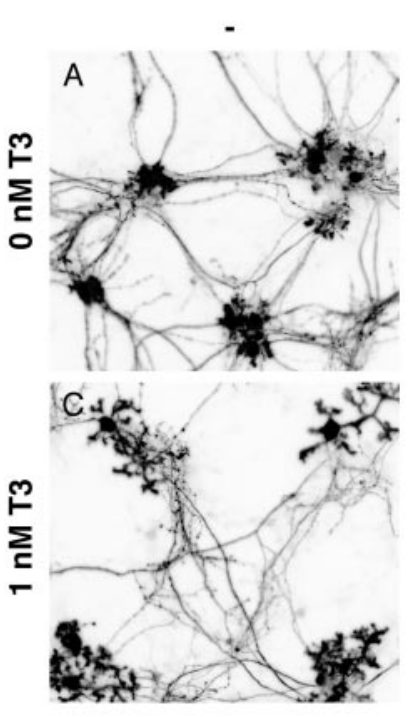

$+20 \mathrm{nM} \mathrm{K252a}$
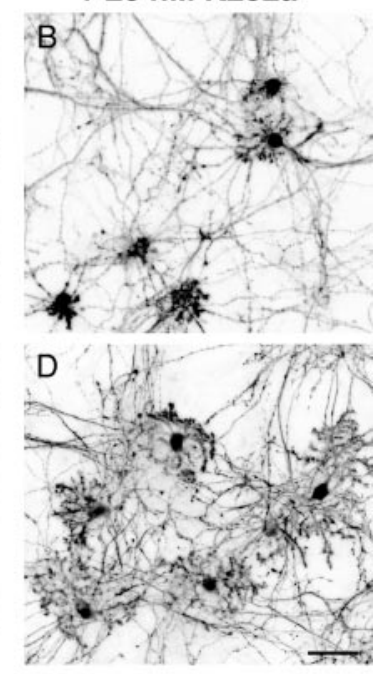

\begin{tabular}{|c|c|c|c|c|}
\hline \multirow{2}{*}{$\begin{array}{l}\text { Purkinje cell } \\
\text { morphology } \\
\text { 0 nM T3 }\end{array}$} & \multicolumn{2}{|c|}{ relative area } & \multicolumn{2}{|c|}{ relative perimeter } \\
\hline & 1 & $( \pm 0,32)$ & 1 & $( \pm 0.50)$ \\
\hline $1 \mathrm{nMT3}$ & 2.54 & $( \pm 1.02)$ & 3.47 & $( \pm 0.69)$ \\
\hline$+2 \mathrm{nM} \mathrm{K} 252 \mathrm{a}$ & 2.01 & $( \pm 0.69)$ & 3.13 & $( \pm 1.33)$ \\
\hline+20 nM K252a & 2.25 & $( \pm 0.62)$ & 4.68 & $( \pm 1.11)$ \\
\hline+20 nM K252b & 2.46 & $( \pm 0.75)$ & 3.31 & $( \pm 0.94)$ \\
\hline
\end{tabular}

Figure 6. K252a dramatically alters Purkinje cell dendritic branching. To block the actions of neurotrophin, mixed cerebellar cultures were also treated for $14 \mathrm{~d}$ with K252a, a Trk-specific inhibitor. $A, C$, Control experiments were performed in the presence of vehicle with or without 1 $\mathrm{nm} \mathrm{T3.} \mathrm{B,} \mathrm{D,} \mathrm{Addition} \mathrm{of} \mathrm{K252a} \mathrm{(} 20 \mathrm{~nm}$ ) did not abolish the effects of T3 on Purkinje cells. However, Purkinje cells develop long, thin, and highly branched dendrites. This effect could be quantified by determining the perimeter as well as the area of these cells. E, Compared with cultures $(0 \mathrm{nM}$ T3) that were only treated with vehicle (DMSO), the area of Purkinje cells increased 2.5 -fold after $\mathrm{T} 3$ treatment. The perimeter, however, increased up to 4.6 -fold if both agents $(20 \mathrm{~nm}$ $\mathrm{K} 252 \mathrm{a}$ and $1 \mathrm{~nm} \mathrm{T3}$ ) were present, thus indicating that dendrites indeed were longer and thinner compared with cells exposed to T3 alone. Adding 2 nм K252a or 20 nм K252b, a nonspecific inhibitor, had no effect on Purkinje cell morphology. Scale bar, $80 \mu \mathrm{m}$.

gous littermates and treated them with or without $1 \mathrm{nM}$ T3 for 14 d. As shown in Figure 5B, Purkinje cells from heterozygous and BDNF-deficient mice respond equally well to T3, with a threefold increase in dendritic parameters.

In another approach, we treated mixed cerebellar cultures for $14 \mathrm{~d}$ with inhibitors of neurotrophin signaling. Soluble TrkB-Fc or TrkC-Fc fusion proteins $(25 \mu \mathrm{g} / \mathrm{ml})$ that consist of TrkB or TrkC extracellular domain fused to the human IgG heavy chain act as scavengers for released neurotrophins (Shelton et al., 1995). However, neither of these agents prevented T3-induced dendritic growth of Purkinje cells (Fig. 5C). Finally, we tried to block Trk receptor activation by blocking the tyrosine kinase activity of the receptor with the inhibitor K252a (Fig. 6) (Berg et al., 1992; Tapley et al., 1992). For this purpose, we incubated mixed cerebellar cultures in the presence (or absence) of K252a with or without 1 nм T3 (Fig. $6 A-D$ ). As shown in Figure $6 D$, addition of $20 \mathrm{~nm}$ K252a did not block T3-induced dendritic growth. However, we noticed a change in dendrite morphology in that K252a-treated Purkinje cells developed very long and thin dendrites. This effect could be quantified by determining the perimeter as well as the area of these cells. Compared with control cultures that were treated with vehicle (DMSO), the perimeter increased up to 4.6fold in the presence of $20 \mathrm{nM} \mathrm{K252a}$ and $1 \mathrm{nM} \mathrm{T3}$ (Fig. 6E). In comparison, $\mathrm{T} 3$ treatment alone induced only a 3.4 -fold increase 
in perimeter, whereas the same T3-induced rise in dendrite area was observed with or without $20 \mathrm{~nm} \mathrm{K252a.} \mathrm{Lower} \mathrm{concentra-}$ tions of $\mathrm{K} 252 \mathrm{a}(2 \mathrm{nM})$ as well as treatment of the cultures with 20 $\mathrm{nM} \mathrm{K252b}$, a nonselective protein kinase inhibitor, did not affect T3-induced morphological changes. These data indicate that treatment of cultures with $20 \mathrm{nM} \mathrm{K} 252 \mathrm{a}$ does indeed lead to longer and thinner dendrites. Because the same morphological changes could be observed in the presence of the protein kinase $\mathrm{C}$ blocker Gö6976 (Metzger and Kapfhammer, 2000) (data not shown), we propose that this effect of K252a is not attributable to a specific interaction with Trk receptors. In conclusion, we were not able to inhibit T3-induced dendrite expansion by blocking neurotrophin signaling, suggesting that, at least in our in vitro culture system, neurotrophin signaling does not collaborate with thyroid hormone signaling to stimulate Purkinje cell dendritic growth.

\section{Discussion}

Dendritic development is thought to be regulated primarily by the presence of afferents, because timing of afferent innervation and synapse formation coincides with the period of maximum growth and dendritic arborization. In addition, dendritic morphology is also thought to be determined by the number and types of synaptic inputs that a neuron receives. Granule cells and their parallel fiber axons, more than climbing fiber axons, play a key role in instigating Purkinje cell differentiation, studied most precisely in purified cocultures (Baptista et al., 1994). However, in vivo, when deprived of parallel fibers, Purkinje cells are capable of developing dendrites and spines, indicating that intrinsic as well as nonafferent derived extrinsic factors contribute to the tightly regulated process of dendritogenesis (Scott and Luo, 2001; Whitford et al., 2002; Wong and Ghosh, 2002)

As an extrinsic factor, thyroid hormone strongly affects dendritogenesis of Purkinje cells. The absence of thyroid hormone during the first postnatal weeks causes profound Purkinje cell hypoplasia and also delays granule cell differentiation. As a consequence, humans as well as rodents suffering from congenital hypothyroidism develop neurological symptoms such as ataxia and poor fine motor movement, emphasizing the importance of proper thyroid hormone supply during cerebellar development. The mechanisms underlying these thyroid hormone effects, however, remain poorly understood. One question is whether thyroid hormone acts on Purkinje cell development directly or instead acts on granule cells, and thus indirectly on Purkinje cells. The generation of mice deficient in thyroid hormone receptors, singly and in combination, has not provided any additional insight with regard to cerebellar action of T3 (O'Shea and Williams, 2002). Neither TR $\beta^{-1-}$ animals that are deficient in all isoforms derived from the TR $\beta$ locus (Forrest et al., 1996) nor mice lacking the TR $\alpha 1$ receptor isoform (Wikström et al., 1998) display any gross cerebellar abnormalities. Surprisingly, even Purkinje cells in $\operatorname{TR} \alpha 1^{-/-} / \beta^{-/-}$mice appear to be quite unaffected (Göthe et al., 1999). However, in all of these receptor-deficient mouse models, the thyroid status is imbalanced and shifted to either hypothyroidism (e.g., in the case of $\operatorname{TR} \alpha 1^{-/-}$) or hyperthyroidism (e.g., in the case of $\mathrm{TR} \beta^{-/-}$). Even tissue-specific hyperthyroidism or hypothyroidism can be observed as in the case of TR $\alpha 2^{-/-}$mice, which overexpress TR $\alpha 1$ (Saltó et al., 2001). Because the thyroid axis is regulated in such a complex manner, compensatory pathways may take place in these TR mouse models that mask the function of each receptor for proper brain development.

Our approach to studying the effects of T3 in primary cerebellar cell cultures offers the opportunity to unravel specific path- ways of T3 action, because the thyroid status can be exactly defined. Furthermore, cells from different thyroid hormone receptor-deficient mouse models can be combined with wildtype cells in vitro and checked for thyroid hormone response. Even direct and indirect effects of T3 can be distinguished, because coculture experiments with purified neuronal cell types allow identification of important receptor isoforms on cellular levels.

By taking advantage of this in vitro system, we focused on the effects of T3 with regard to Purkinje cell dendritogenesis. Addition of T3 to otherwise complete athyroid mixed cerebellar cell cultures revealed a dramatic increase in dendritic outgrowth of Purkinje cells in a dose-dependent manner, an observation that is in agreement with results published recently (Kimura-Kuroda et al., 2002). Purkinje cell soma and dendritic tree dimensions increase up to threefold within $14 \mathrm{~d}$ in vitro, reaching a plateau at 3 $\mathrm{nM}$ T3. This potent effect is observed only during continuous T3 exposure, indicating that the function of $\mathrm{T} 3$ is not restricted to serving as a molecular switch to initiate Purkinje cell maturation.

Which receptor isoform is involved in this process? Theoretically, both receptors could participate, because both receptors are expressed during cerebellar development. From our results, however, we can conclude that TR $\beta 1$, although expressed in Purkinje cells during the peak of dendrite formation (Strait et al., 1991), is not essential. Our data emphasize a pivotal role for $\mathrm{TR} \alpha 1$, a receptor isoform highly expressed in granule as well as in Purkinje cells (Bradley et al., 1992). For T3-promoted dendritogenesis, however, TR $\alpha 1$ must be expressed in Purkinje cells, because the absence of TR $\alpha 1$ in granule cells does not interfere with the Purkinje cell response. Therefore, we can exclude an indirect effect by which T3 acts on granule cells, which, in turn, would release growth factors to control Purkinje cell dendritogenesis. In contrast, our results clearly demonstrate for the first time that Purkinje cells are a direct target of T3 action.

Why is only TR $\alpha 1$ but not TR $\beta 1$ essential for promoting T3induced dendritogenesis? At first glance, this finding is surprising, because both receptors are closely related in their DNA- and T3-binding domain and can transactivate through similar TREs. However, differences in the conformation of $\operatorname{TR} \alpha 1$ and $\operatorname{TR} \beta$ could result in differential recognition of TREs or interaction with cofactors (Forrest et al., 2002). Indeed, several studies have postulated isoform-specific functions. In the kidney, T3dependent regulation of deiodinase type 1 expression relies solely on TR $\beta$ despite the expression of both TRs (Amma et al., 2001). Alternatively, it has been proposed that TRs are essentially interchangeable, and that it is the total level of TR expression in a cell that determines its response to TH (Yen et al., 2003). In line with this argument, one has to assume that $\operatorname{TR} \alpha 1$ is the major functional isoform in Purkinje cells, because TR $\beta$ cannot compensate for the absence of TR $\alpha 1$.

Signaling of TR $\alpha 1$ seems to be complex and involves at least two different mechanisms. Binding of T3 to TR $\alpha 1$ can obviously promote dendritic arborization, most likely by inducing expression of genes involved in this process. Without T3, however, unliganded TR $\alpha 1$ can also bind to DNA and act as a repressor of gene transcription. In our cell culture system, unliganded TR $\alpha 1$ appears to repress dendrite formation, because Purkinje cells lacking TR $\alpha 1$ show a higher degree of dendritic arborization than wild-type Purkinje cells under T3-free culture conditions. This in vitro observation is in agreement with studies by Morte et al. (2003), who showed an insensitivity of Purkinje cells in TR $\alpha 1^{-/-}$ animals to drug-induced hypothyroidism. Additionally, Purkinje cells are abnormally developed in mice expressing dominant- 
negative forms of TR that lack T3 binding capacity (Hashimoto et al., 2001; Kaneshige et al., 2001). Together, these findings imply that thyroid hormone receptors can regulate transcription by both T3-dependent and T3-independent means. Furthermore, absence of T3-induced derepression of gene transcription might be the primary reason for the severe cerebellar abnormalities found under hypothyroid conditions (Göthe et al., 1999).

Which genes are positively or negatively regulated by $\mathrm{TR} \alpha 1^{-1-}$ action and mediate T3-induced dendrite formation? Neurotrophins appeared to be attractive candidates, because their expression patterns have been shown to be tightly regulated by $\mathrm{T} 3$ and in the hypothyroid cerebellum (e.g., BDNF mRNA levels are suppressed) (Koibuchi et al., 1999). Moreover, grafting cell lines expressing BDNF or NT3 into the fourth ventricle in part, but not completely, prevents hypothyroidism-induced abnormal cerebellar development (Neveu and Arenas, 1996). In addition, BDNF has been shown to regulate the growth and branching of cortical pyramidal neuron dendrites (McAllister et al., 1995; Miller and Kaplan, 2003). Thus, a similar role of BDNF in Purkinje cell development was an obvious assumption supported by the fact that $\mathrm{BDNF}^{-1-}$ mice exhibit a decreased arborization of Purkinje cell dendrites and a delayed migration of granule cells (Schwartz et al., 1997), a phenotype similar to that in hypothyroid rodents. For these reasons, we analyzed the role of neurotrophin signaling with regard to T3-induced Purkinje cell dendritogenesis in our cell culture system. Unexpectedly, Purkinje cells derived from $\mathrm{BDNF}^{-1-}$ mice displayed the same T3 responsiveness as wild-type cells. In addition, blocking the actions of neurotrophin or adding BDNF did not affect T3-induced dendritogenesis, particularly in terms of the extent and caliber of dendritic pattern, similar to our findings on the role of BDNF in Purkinje cell dendritogenesis (Morrison and Mason, 1998). Blocking BDNF, however, did affect spine morphology, again, as we found previously (Shimada et al., 1998). Therefore, we conclude that neurotrophin signaling, although crucial for granule cell development (Borghesani et al., 2002), does not directly participate in T3-induced Purkinje cell dendritogenesis.

The challenge still ahead is to unravel the mechanisms by which T3 promotes dendrite formation. The experiments presented here using Purkinje cells deficient in the TR $\alpha 1$ isoform indicate that T3 exerts its powerful effect directly on Purkinje cells, whereas the actions of $\mathrm{T} 3$ on granule cells appear to have only minor consequences for Purkinje cell dendritogenesis. We cannot exclude that granule cells release other growth factors or signaling molecules in response to T3 that support Purkinje cell differentiation. However, to boost dendritogenesis, T3 signaling must be activated within the Purkinje cell.

In conclusion, understanding dendritic development requires knowledge of the mechanisms that coordinate the overall growth and detailed patterning of Purkinje cell arborization. Elucidating the actions of thyroid hormone during Purkinje cell dendrite formation provides an excellent paradigm to explore the intracellular signaling pathways that mediate this process. Here we have shown that the interaction of T3 with TR $\alpha 1$ in Purkinje cells defines one crucial step in proper dendrite formation. Based on this information, future attention should be focused on identifying downstream genes regulated by $\mathrm{TR} \alpha 1$.

\section{References}

Amma LL, Campos-Barros A, Wang Z, Vennström B, Forrest D (2001) Distinct tissue-specific roles for thyroid hormone receptors $\beta$ and $\alpha 1$ in regulation of type 1 deiodinase expression. Mol Endocrinol 15:467-475.

Anderson GW (2001) Thyroid hormones and the brain. Front Neuroendocrinol 22:1-17.
Baptista CA, Hatten ME, Blazeski R, Mason CA (1994) Cell-cell interactions influence survival and differentiation of purified Purkinje cells in vitro. Neuron 12:243-260.

Berg MM, Sternberg DW, Parada LF, Chao MV (1992) K-252a inhibits nerve growth factor-induced Trk proto-oncogene tyrosine phosphorylation and kinase activity. J Biol Chem 267:13-16.

Borghesani PR, Peyrin JM, Klein R, Rubin J, Carter AR, Schwartz PM, Luster A, Corfas G, Segal RA (2002) BDNF stimulates migration of cerebellar granule cells. Development 129:1435-1442.

Bradley DJ, Young WS, Weinberger C (1989) Differential expression of $\alpha$ and $\beta$ thyroid hormone receptor genes in rat brain and pituitary. Proc Natl Acad Sci USA 86:7250-7254.

Bradley DJ, Towle HC, Young WS (1992) Spatial and temporal expression of $\alpha$ - and $\beta$-thyroid hormone receptor mRNAs, including the $\beta 2$ subtype, in the developing mammalian nervous system. J Neurosci 12:2288-2302.

Ehrchen J, Heuer H, Sigmund R, Schäfer MKH, Bauer K (2001) Expression and regulation of osteopontin and connective tissue growth factor transcripts in rat anterior pituitary. J Endocrinol 169:87-96.

Ernfors P, Lee KF, Jaenisch R (1994) Mice lacking brain-derived neurotrophic factor develop with sensory deficits. Nature 368:147-150.

Forrest D, Vennström B (2000) Functions of thyroid hormone receptors in mice. Thyroid 10:41-52.

Forrest D, Hanebuth E, Smeyne RJ, Everds N, Stewart CL, Wehner JM, Curran $\mathrm{T}$ (1996) Recessive resistance to thyroid hormone in mice lacking thyroid hormone receptor $\beta$ : evidence for tissue-specific modulation of receptor function. EMBO J 15:3006-3015.

Forrest D, Reh TA, Rüsch A (2002) Neurodevelopmental control by thyroid hormone receptors. Curr Opin Neurobiol 12:49-56.

Friedrichsen S, Christ S, Heuer H, Schäfer MKH, Mansouri A, Bauer K, Visser TJ (2003) Regulation of iodothyronine deiodinases in the Pax $8^{-1-}$ mouse model of congenital hypothyroidism. Endocrinology 144:777-784.

Göthe S, Wang Z, Ng L, Kindblom JM, Barros AC, Ohlsson C, Vennström B, Forrest D (1999) Mice devoid of all known thyroid hormone receptors are viable but exhibit disorders of the pituitary-thyroid axis, growth, and bone maturation. Genes Dev 13:1329-1341.

Hashimoto K, Curty FH, Borges PP, Lee CE, Abel ED, Elmquist JK, Cohen RN, Wondisford FE (2001) An unliganded thyroid hormone receptor causes severe neurological dysfunction. Proc Natl Acad Sci USA 98:3998-4003.

Hatten ME (1985) Neuronal regulation of astroglial morphology and proliferation in vitro. J Cell Biol 100:384-396.

Hatten ME, Gao W, Morrison ME, Mason CA (1998) The cerebellum: purification and coculture of identified cell populations. In: Culturing nerve cells (Banker G, Goslin K, eds), pp 419-458. Cambridge, MA: MIT.

Kaneshige M, Suzuki H, Kaneshige K, Cheng J, Wimbrow H, Barlow C, Willingham MC, Chen SY (2001) A targeted dominant negative mutation of the thyroid hormone $\alpha 1$ receptor causes increased mortality, infertility, and dwarfism in mice. Proc Natl Acad Sci USA 98:15095-15100.

Kimura-Kuroda J, Nagata I, Negishi-Kato M, Kuroda Y (2002) Thyroid hormone-dependent development of mouse cerebellar Purkinje cells in vitro. Brain Res Dev Brain Res 137:55-65.

Koibuchi N, Chin WW (2000) Thyroid hormone action and brain development. Trends Endocrinol Metab 11:123-128.

Koibuchi N, Fukuda H, Chin WW (1999) Promoter-specific regulation of the BDNF gene by thyroid hormone in the developing rat cerebellum. Endocrinology 140:3955-3961.

Lauder JM (1977) Effects of thyroid state on development of rat cerebellar cortex. In: Thyroid hormones and brain development (Grave GD, ed), pp 235-254. New York: Raven.

Lauder JM (1978) Effects of early hypo- and hyperthyroidism on development of rat cerebellar cortex. IV. The parallel fibers. Brain Res 142:25-39.

Legrand J (1984) Effects of thyroid hormones on central nervous system development. In: Neurobehavioural teratology (Yanai J, ed), pp 331-363. Amsterdam: Elsevier.

Lindholm D, Castren E, Tsoulfas P, Kolbeck R, da Penha Berzaghi M, Leingärtner A, Heisenberg CP, Tesarollo L, Parada LF, Thoenen H (1993) Neurotrophin-3 induced by tri-iodothyronine in cerebellar granule cells promotes Purkinje cell differentiation. J Cell Biol 122:443-450.

Mangelsdorf DJ, Thummel C, Beato M, Herrlich P, Schutz G, Umesono K, Blumberg B, Kastner P, Mark M, Chambon P (1995) The nuclear receptor superfamily: the second decade. Cell 83:835-839. 
McAllister AK, Lo DC, Katz LC (1995) Neurotrophins regulate dendritic growth in developing visual cortex. Neuron 15:791-803.

Mellström B, Naranjo JR, Santos A, Gonzalez AM, Bernal J (1991) Independent expression of the $\alpha$ and $\beta$ c-erbA genes in developing rat brain. Mol Endocrinol 5:1339-1350.

Metzger F, Kapfhammer JP (2000) Protein kinase C activity modulates dendritic differentiation of rat Purkinje cells in cerebellar slice cultures. Eur J Neurosci 12:1993-2005.

Miller FD, Kaplan DR (2003) Signaling mechanisms underlying dendrite formation. Curr Opin Neurobiol 13:391-398.

Morrison ME, Mason CA (1998) Granule neuron regulation of Purkinje cell development: striking a balance between neurotrophin and glutamate signaling. J Neurosci 18:3565-3573.

Morte B, Manzano J, Scanlan T, Vennström B, Bernal J (2002) Deletion of the thyroid hormone receptor $\alpha 1$ prevents the structural alterations of the cerebellum induced by hypothyroidism. Proc Natl Acad Sci USA 99:3985-3989.

Neveu I, Arenas E (1996) Neurotrophins promote the survival and development of neurons in the cerebellum of hypothyroid rats in vivo. J Cell Biol 133:631-646.

Nicholson JL, Altman J (1972) The effects of early hypo- and hyperthyroidism on the development of the rat cerebellar cortex. II. Synaptogenesis in the molecular layer. Brain Res 44:25-36.

Oppenheimer JH, Schwartz HL (1997) Molecular basis of thyroid hormone-dependent brain development. Endocr Rev 18:462-475.

O'Shea PJ, Williams GR (2002) Insight into the physiological actions of thyroid hormone receptors from genetically modified mice. J Endocrinol 175:553-570.

Porterfield SP, Hendrich CE (1993) The role of thyroid hormones in prenatal and neonatal neurological development: current perspectives. Endocr Rev 14:94-106.

Saltó C, Kindblom JM, Johannsson C, Wang Z, Gullberg H, Nordström K, Mansén A, Ohlsson C, Thorén P, Forrest D, Vennström B (2001) Ablation of TR $\alpha 2$ and a concomitant overexpression of $\alpha 1$ yields a mixed hypo- and hyperthyroid phenotype in mice. Mol Endocrinol 15:2115-2128.

Schwartz PM, Borghesani PR, Sevy RL, Pomeroy SL, Segal RA (1997) Ab- normal cerebellar development and foliation in $\mathrm{BDNF}^{-1-}$ mice reveals a role for neurotrophins in CNS patterning. Neuron 19:269-281.

Scott EK, Luo L (2001) How do dendrites take their shape? Nat Neurosci 4:359-365.

Shelton DL, Sutherland J, Gripp J, Camerato T, Armanini MP, Phillips HS, Carroll K, Spencer SD, Levinson AD (1995) Human trks: molecular cloning, tissue distribution, and expression of extracellular domain immunoadhesins. J Neurosci 15:477-491.

Shimada A, Mason CA, Morrison ME (1998) TrkB signaling modulates spine density and morphology independent of dendrite structure in cultured neonatal Purkinje cells. J Neurosci 18:8559-8570.

Strait KA, Schwartz HL, Seybold VS, Ling NC, Oppenheimer JH (1991) Immunofluorescence localization of thyroid hormone receptor protein $\beta 1$ and variant $\alpha 2$ in selected tissues: cerebellar Purkinje cells as a model for $\beta 1$-mediated developmental effects of thyroid hormone in brain. Proc Natl Acad Sci USA 88:3887-3891.

Tapley P, Lamballe F, Barbacid M (1992) K252a is a selective inhibitor of the tyrosine protein kinase activity of the Trk family of oncogenes and neurotrophin receptors. Oncogene 7:371-381.

Vincent J, Legrand C, Rabié A, Legrand J (1982-1983) Effects of thyroid hormone on synaptogenesis in the molecular layer of the developing cerebellum. J Physiol (Paris) 78:729-738.

Whitford KL, Dijkhuizen P, Polleux F, Ghosh A (2002) Molecular control of cortical dendrite development. Annu Rev Neurosci 25:127-149.

Wikström L, Johannsson C, Saltó C, Barlow C, Barros AC, Baas D, Forrest D, Thorén P, Vennström B (1998) Abnormal heart rate and body temperature in mice lacking thyroid hormone receptor $\alpha 1$. EMBO J 17:455-461.

Wong RO, Ghosh A (2002) Activity-dependent regulation of dendritic growth and patterning. Nat Rev Neurosci 3:803-812.

Wu Y, Koenig RJ (2000) Gene regulation by thyroid hormone. Trends Endocrinol Metab 11:207-211.

Yen PM, Feng X, Flamant F, Chen Y, Chen Y, Walker RL, Weiss RE, Chassande O, Samarut J, Refetoff S, Meltzer PS (2003) Effects of ligand and thyroid hormone receptor isoforms on hepatic gene expression profiles of thyroid hormone receptor knockout mice. EMBO Rep 4:581-587.

Zhang J, Lazar MA (2000) The mechanism of action of thyroid hormones. Annu Rev Physiol 62:439-466. 